\title{
Fish melanocortin system
}

José Miguel Cerdá-Reverter ${ }^{1 *}$, Maria Josep Agulleiro ${ }^{1}$, Raúl Guillot $\mathrm{R}^{1}$, Elisa Sánchez ${ }^{1}$, Rosa Ceinos $^{2}$, Josep Rotllant ${ }^{2}$

${ }^{1}$ Department of Fish Physiology and Biotechnology, Instituto de Acuicultura de Torre de la Sal (IATS), Consejo Superior de Investigaciones Científicas (CSIC), Castellón, SPAIN. ${ }^{2}$ Instituto de Investigaciones Marinas (IIM), CSIC, Vigo, SPAIN

* Corresponding author and reprint requests: Dr. J.M. Cerdá-Reverter, Department of Fish Reproductive Physiology, Instituto de Acuicultura de Torre de la Sal, 12595 Torre de la Sal, Ribera de Cabanes, Castellón, SPAIN. E-mail Address: cerdarev@iats.csic.es, Phone Number: (+) 34 964319500, Fax: (+) 34964319509. 


\begin{abstract}
Melanocortin signalling is mediated by binding to a family of $G$ protein-coupled receptors that positively couple to adenylyl cyclase. Tetrapod species have five melanocortin ( $\left.\mathrm{MC}_{1}-\mathrm{MC}_{5}\right)$ receptors. The number of receptors varies in fish, zebrafish, for example, having six melanocortin receptors, with two copies of the melanocortin $\mathrm{MC}_{5}$ receptor, while pufferfish have 4 receptors with no melanocortin $\mathrm{MC}_{3}$ receptor and one copy of melanocortin $\mathrm{MC}_{5}$ receptor. Fish genomes also exhibit orthologue genes for agouti-signalling protein (ASP) and -related protein (AGRP). AGRP expression is confined to a small area in the hypothalamus but ASP is expressed in the skin. Fish melanocortin $\mathrm{MC}_{2}$ receptor is specific for $\mathrm{ACTH}$ and requires the cooperation of accessory proteins (MRAP) to reach functional expression. The four other melanocortin MC receptors distinctively bind MSHs. The interaction of $\alpha-\mathrm{MSH}$ and melanocortin $\mathrm{MC}_{1}$ receptor plays a key point in the control of the pigmentation and mutations of melanocortin $\mathrm{MC}_{1}$ receptor are responsible for reduced melanization. Both melanocortin $\mathrm{MC}_{4}$ and $\mathrm{MC}_{5}$ receptor are expressed in the hypothalamus, and central melanocortin $\mathrm{MC}_{4}$ receptor expression is thought to regulate the energy balance through the modulation of feeding behaviour. In addition, the peripheral melanocortin system also regulates lipid metabolism by acting at hepatic melanocortin $\mathrm{MC}_{2}$ and $\mathrm{MC}_{5}$ receptors. Both sea bass melanocortin $\mathrm{MC}_{1}$ and $\mathrm{MC}_{4}$ receptors are constitutively expressed in vitro and both ASP and AGRP work as inverse agonists but only after inhibition of the phosphodiesterase system. Accordingly, the overexpression of AGRP and ASP transgenes promotes obesity and reduces melanization in zebrafish, respectively.
\end{abstract}

Keywords: Melanocortin-stimulating hormone (MSH); Proopiomelanocortin (POMC); Agoutisignalling protein (ASIP); Agouti-related protein (AGRP); Melanocortin Receptor; Melanocortin receptor accessory protein (MRAP); Food Intake; Pigmentation; Stress 


\section{Introduction}

Proopiomelanocortin (POMC) gene encodes a complex protein precursor that belongs to the opioid/orphanin gene family, which also includes proenkephalin, prodynorphin and proorphanin. This opioid/orphanin system was mainly formed by the two genome duplication rounds (2R) and probably a local duplication event during vertebrate evolution (Sundström et al., 2010). Tetrapod POMC precursor comprises three main domains: the $\mathrm{N}$-terminal pro- $\boldsymbol{\gamma}$-melanocyte stimulating hormone (MSH), the central adrenocorticotropic hormone (ACTH) and the C-terminal $\beta$-lipotropin. Each domain contains one MSH peptide delineated by a core sequence HFRW: $\gamma$-MSH in pro- $\gamma$ MSH, $\alpha$-MSH as N-terminal sequence of ACTH and $\beta$-MSH in $\beta$-lipotropin domain. The last domain further includes the C-terminal $\beta$-endorphin opioid peptide (Nakanishi et al., 1979). The three-domain structure has also been reported in invertebrate species, suggesting that this organization represents a plesiomorphic character, although classical melanocortin receptors have been never reported in invertebrates (Stefano et al., 1993). The number of MSH domains varies in fish, depending on the taxonomic class. Ray-finned fish exhibit substitutions in the $\gamma$-MSH core (basal groups) or deletion (teleost fish). Lobe finned fish, including lungfish and coelacanth, inherited the three-domain ancestral condition but cartilaginous fish exhibit an additional $\delta$-domain located between $\alpha$ - and $\beta$-MSH. An independent duplication event in agnathans coupled to specialization resulted in two genes, POC and POM, showing ACTH and MSHs domains, respectively (Takahashi and Kawauchi, 2006). Avian and mammalian species have a single copy of the POMC gene but the genome of teleost antecessor doubled once more (3R) resulting in an expansion of the receptor/peptide systems. This event, together with particular tetraploidization events (e.g. salmonids), have resulted in additional copies of POMC in the genome of teleost fish. Sequencing projects have led to the conclusion that teleost fish, including zebrafish (Danio rerio), medaka (Oryzias latipes), three-spined stickleback (Gasterosteus aculeatus) and the puffefishes (Takifugu rubripes and Tetraodon nigroviridis) exhibit two POMC (POMCa or $\alpha$ and POMCb or 
ß) paralogue genes (González-Nunez et al., 2003; Sundström et al., 2010). In addition, three different forms (a1, a2 and b) have been reported in barfin flounder (Verasper moseri; Takahashi et al., 2005). Studies in zebrafish suggest a subfunctionalization of the ancestral POMC sharing functions with the new paralogue gene in teleost fish (de Souza et al., 2005)

Tetrapod POMC is mainly produced in the vertebrate pituitary and its posttranslational processing occurs in a tissue-specific manner. The proteolytic cleavage of POMC by prohormone convertase 1 $\left(\mathrm{PC}_{1}\right)$ generates $\mathrm{ACTH}$ and $\beta$-lipotropin $(\beta-\mathrm{LPH})$ in the corticotrophs of the anterior pituitary, whereas cleavage by $\mathrm{PC}_{1}$ and $\mathrm{PC}_{2}$ produces $\alpha-\mathrm{MSH}$ and $\beta$-endorphin in the melanotrophs of the pars intermedia (Castro and Morrison 1997). As in other vertebrate species, fish POMC is mainly expressed in the pituitary gland. Two pituitary cell types produce melanocortin precursor. Corticotropes or ACTH-producing cells are localized in the rostral pars distalis, whereas melanotropes or MSH-producing cells are localized within the pars intermedia which is heavily innervated from the neurohypophysis to form the neurointermediate lobe in teleost fish (CerdáReverter and Canosa, 2009). The number of POMC cells is notably smaller within the rostral pars distalis than pars intermedia, which reflects the preferential isolation of $\alpha-\mathrm{MSH}, \beta-\mathrm{MSH}$ and $\beta$ endorphin from the whole pituitary extracts (Takahashi and Kawauchi, 2006). Recent studies have demonstrated the differential processing of POMC in the pituitary of teleost fish (Takahashi et al., 2006). Therefore, N-terminal POMC (equivalent to $\gamma$-MSH domain of tetrapods), des-acetyl $\alpha$ MSH, $\alpha$ - MSH, CLIP (corticotropin-like intermediate peptide), N- $\beta$-LPH, $\beta$-MSH and N-acetyl- $\beta$ endorphin has been isolated from the pars intermedia. This processing pathway in the pars intermedia is similar to that reported in mammalian species (Castro and Morrison, 1997). In the rostral pars distalis, N-POMC and ACTH have been isolated, as have des-acetyl $\alpha$-MSH, CLIP and $\beta$-MSH. This suggests that, as in the mammalian system, ACTH is also produced within the pars distalis although this peptide may be further cleaved to des-acetyl $\alpha$ - MSH and CLIP, suggesting that corticotropes of the rostral pars distalis lack a MSH-acetylating system (Takahashi et al., 
2008).

In mammalian species, POMC is also centrally produced and mainly processed to $\alpha$-MSH and $\beta$ endorphin (Castro and Morrison, 1997). In rodents, two discrete groups of neurons in the hypothalamus (arcuate nucleus) and the medulla (nucleus of the tractus solitarius) also produce POMC (Bangol et al., 1999). POMC mRNA expression within the mediobasal hypothalamus has been conserved throughout vertebrate evolution, as POMC transcripts have been detected in hypothalamic neuronal systems of amphibians (Tuinhof et al., 1998), birds (Gerets et al., 2000). Our experiments in goldfish have demonstrated that POMC is also expressed within the whole extension rostro-caudal extension of the lateral tuberal nucleus, which is thought to be the teleostean homologue of the arcuate nucleus (Cerdá-Reverter et al., 2003a). However, no POMC expression within the vagal lobe, the teleostean nucleus of the tractus solitarius, has been reported in any teleost species. Unfortunately, no information about POMC processing within the central nervous system is available.

Melanocortin exerts its physiological role by binding to a family of specific G protein-coupled receptors that positively couple to adenylyl cyclase. Tetrapod species have five melanocortin $\left(\mathrm{MC}_{1-}\right.$ $\mathrm{MC}_{5}$ ) receptors. In mammalian systems, melanocortin $\mathrm{MC}_{2}$ receptor is specific for $\mathrm{ACTH}$. The four other $\mathrm{MC}$ receptors bind to MSHs, with melanocortin $\mathrm{MC}_{1}$ and $\mathrm{MC}_{3}$ receptors exhibiting the highest affinity for $\alpha$-MSH and $\gamma$-MSH respectively (reviewed by Schiöth et al., 2005). Again, the number of receptors diverges in teleost fish. Zebrafish has six MC receptors, with two copies of the melanocortin $\mathrm{MC}_{5}$ receptor, while pufferfish have only 4 receptors with no melanocortin $\mathrm{MC}_{3}$ receptor and only one copy of melanocortin $\mathrm{MC}_{5}$ receptor (Logan et al., 2003). Interestingly, perciform fish genome, the youngest teleost fish, lacks melanocortin $\mathrm{MC}_{3}$ receptor and $\gamma$-MSH domain in the POMC gene, suggesting co-evolution of the peptide/receptor system. Atypically, melanocortin signalling is not exclusively regulated by binding of endogenous agonists, as naturally occurring antagonists, agouti-signalling protein (ASP) and agouti-related protein (AGRP), compete with melanocortin peptides by binding to MC receptors. ASP is a potent 
melanocortin antagonist at melanocortin $\mathrm{MC}_{1}$ and $\mathrm{MC}_{4}$ receptors and relatively weak at melanocortin $\mathrm{MC}_{3}$ receptor. In mice, ASP is exclusively produced within the hair follicle and it locally regulates the production of pigment in follicular melanocytes by antagonizing the effects of $\alpha-\mathrm{MSH}$ on melanocortin $\mathrm{MC}_{1}$ receptor. In contrast, $\mathrm{AGRP}$ is mainly produced within the hypothalamic arcuate nucleus and the adrenal gland and it strongly inhibits melanocortin signaling at melanocortin $\mathrm{MC}_{3}$ and $\mathrm{MC}_{4}$ receptors, but is not active at melanocortin $\mathrm{MC}_{1}$ receptor (Cone, 2006).

Several studies have demonstrated that mammalian ASP and AGRP work as inverse agonists at melanocortin $\mathrm{MC}_{4}$ receptor which is constitutively activated (Nijenhuis et al., 2001; Chai et al., 2003). Therefore, melanocortin $\mathrm{MC}_{4}$ receptor signals in the absence of agonist binding. AGRP or ASP reduces constitutive melanocortin $\mathrm{MC}_{4}$ receptor signaling in a dose-dependent manner. The presence of melanocortin endogenous antagonist including AGRP and ASP in fish was first demonstrated in goldfish (Cerdá-Reverter and Peter, 2003, Cerdá-Reverter et al., 2005) and later in several teleost species (Song et al., 2003; Kurokawa et al., 2006; Murashita et al., 2009). Once again, paralogue genes for both ASIPs $\left(\mathrm{ASIP}_{1}\right.$ and $\left.\mathrm{ASIP}_{2}\right)$ and $\mathrm{AGRPs}\left(\mathrm{AGRP}_{1}\right.$ and $\left.\mathrm{AGRP}_{2}\right)$ have been demonstrated in teleost (Kurokawa et al., 2006; Murashita et al., 2009). In goldfish, zebrafish and salmon, $\mathrm{AGRP}_{1}$ is expressed in several peripheral tissues, including skin, but in the central nervous system it is solely expressed within the lateral tuberal nucleus where POMC is also produced (Cerdá-Reverter et al., 2003 Forlano and Cone, 2008). In contrast, $\mathrm{AGRP}_{2}$ is only expressed in the pineal gland of the zebrafish but quantitative PCR (qPCR) studies in salmon have demonstrated wider $\mathrm{AGRP}_{2}$ expression at the periphery (Murashita et al., 2009). Unlike in the mammalian system, AGRP works as an inverse agonist and competitive antagonist at both sea bass melanocortin $\mathrm{MC}_{1}$ and $\mathrm{MC}_{4}$ receptors. ASIP is also widely expressed in the periphery despite a certain degree of central expression. In the periphery, ASIP is mainly expressed in the skin, where it is supposed to participate in the acquisition of the adult pigment pattern (Cerdá-Reverter et al., 2005) 


\section{Melanocortins and food intake}

Studies by Northern blot in goldfish (Cerdá-Reverter et al., 2003a), whole-mount in situ hybridization in zebrafish (Song et al., 2003) and qPCR in sea bass have demonstrated that POMC hypothalamic neurons cannot respond to progressive fasting that induces a severe reduction in weight (Sánchez et al., 2009a). Similar results have also been obtained in mammalian species. Therefore, POMC mRNA remain unchanged in chronically food-restricted sheep suffering about 40\% total body-weight loss (Henry et al., 2001) and long-term alterations in adiposity do not affect hypothalamic POMC expression in ovarectomized ewes that have lost about 30\% total body weight (Henry et al., 2000). However, intracerebroventricular injections of melanocortin agonist, NDPMSH ([Nle4, D-Phe7] $\alpha-M S H)$, or MTII (Ac-Nle-Asp-His-D-Phe-Arg-Trp-Lys-NH2), inhibit food intake in goldfish (Cerdá-Reverter et al., 2003a,b) and rainbow trout (Schjolden et al., 2009) in a dose dependent way. Accordingly, intracerebroventricular administration of HS024 (cyclo Ac-CysNle-Arg-His-D-Nal-Arg-Trp-Gly-Cys-NH2), in fed goldfish increased food intake four hours after treatment (Cerdá-Reverter et al., 2003b). Similar results were obtained in rainbow trout when using and SHU9119 (Ac-Nle-cyclo(Asp-His-D-2-Nal-Arg-Trp-Lys)-NH2), although the former had a more pronounced effect on food intake (Schjolden et al., 2009). These results suggest that the melanocortin system may be involved in the control of food intake of fish , although the lack of hypothalamic response to fasting leads to reservations concerning how the system is regulated. In the absence of a POMC hypothalamic response, the system can be regulated at three different levels at least: i) differential processing of POMC precursor after progressive fasting. Of note is the fact that the intracerebroventricular administration of $\beta$-endorphin, which is encoded at the C-terminal end of POMC, has been shown to stimulate appetite in the goldfish (De Pedro et al., 1995). Because of the contrasting actions of POMC peptides on food intake, the effects of nutritional status might manifest themselves at posttranscriptional levels by the differential regulation of the prohormone 
convertases involved in goldfish POMC processing. In food-restricted goldfish with enhanced feeding drive, POMC cleavage may be directed towards the production of $\beta$-endorphin, whereas a positive energy balance may preferentially drive POMC processing to production of the food-intake inhibitor $\alpha$-MSH. However, no experiments in fish have tested this hypothesis. ii) Adjustment in the number of central melanocortin receptors. The system could also be regulated by alteration of the receptor density in areas controlling food intake. Therefore, during fasting, the availability of receptors could be reduced, thus decreasing sensitivity to endogenous melanocortin peptides or constitutive signalling. Experiments in barfin flounder (Verasper mosari) and sea bass have demonstrated that progressive fasting does not modify melanocortin $\mathrm{MC}_{4}$ receptor mRNA expression levels in the hypothalamus (Kobayashi et al., 2008; Sánchez et al., 2009a) but no experiments have been carried out to evaluate the availability of the receptor at the plasma membrane iii) Counter regulation of receptor activity by the central melanocortin antagonists or inverse agonists. It is plausible that the activity of the receptor is basically regulated by the action of an inverse agonist, whereas proper agonists only work under specific physiological conditions. Experiments in goldfish (Cerdá-Reverter and Peter 2003) and zebrafish (Song et al., 2003) demonstrated that hypothalamic AGRP expression is dramatically increased during fasting at the same time intervals in which POMC expression remains constant. Our pharmacological experiments in goldfish and sea bass melanocortin receptors have demonstrated that zebrafish AGRP (83-127) is a potent competitive antagonist at sea bass melanocortin $\mathrm{MC}_{4}$ receptor (Sánchez et al., 2009a) but not at sea bass melanocortin $\mathrm{MC}_{5}$ receptor (Sánchez et al., 2009b). The C-terminal fragment of the zebrafish AGRP can also work as an inverse agonist, inhibiting both basal and forskolin-induced melanocortin $\mathrm{MC}_{4}$ receptor activity (Sánchez et al., 2009a; Sánchez et al., 2010). Suggestively, sea bass melanocortin $\mathrm{MC}_{4}$ receptor constitutive activity and/or AGRP inverse agonism, but not competitive antagonism, depends on inhibition of the intracellular phosphodiesterase system when the receptor is overexpressed in human embryonic kidney (HEK)293 cells. This suggests that both AGRP agonism and antagonism in the sea bass melanocortin $\mathrm{MC}_{4}$ 
receptor system are mediated through different intracellular signalling pathways with differential sensitivities to phosphodiesterase inhibitors. To the best of our knowledge, such phosphodiesterase dependence has been only studied in the sea bass melanocortin $\mathrm{MC}_{1}$ and $\mathrm{MC}_{4}$ receptors and this opens new targets for investigation of melanocortin-induced metabolic syndrome.

Both HS024 and SHU9119 have been demonstrated to work as functional competitive antagonists at sea bass melanocortin $\mathrm{MC}_{4}$ receptor (Cerdá-Reverter et al., 2003b; Sánchez et al., 2009a; Sánchez et al, 2010). However, both compounds are potent agonists in goldfish melanocortin $\mathrm{MC}_{5}$ receptor (Cerdá-Reverter et al., 2003c) and sea bass melanocortin $\mathrm{MC}_{5}$ receptor (Sánchez et al., 2009b), suggesting that the central melanocortin effects on food intake are mediated via melanocortin $\mathrm{MC}_{4}$ receptor. In situ hybridization studies in goldfish (Cerdá-Reverter et al., 2003b) and sea bass (Sánchez et al., 2009a) have demonstrated that this receptor is profusely expressed within the CNS. In fact, sea bass melanocortin $\mathrm{MC}_{4}$ receptor expression is basically restricted to the CNS, while goldfish melanocortin $\mathrm{MC}_{4}$ receptor is also expressed in the peripheral tissues. Sea bass receptor transcripts are restricted to the telencephalon, preoptic area, ventral thalamus, tuberal and lobular hypothalamus, optic tectum and rombencephalon. The distribution of the receptor in goldfish brain is similar to that reported in sea bass, with transcripts within the rostral telencephalon, preoptic area and tuberal hypothalamus. Experiments in zebrafish (Forlano and Cone, 2007) and seabass (Ríos, Agulleiro, Leal, Cerdá-Reverter, unpublished results) suggest that melanocortin $\mathrm{MC}_{4}$ receptor distribution is consistent with the localization of MSH/AGRP immunoreactive terminals. In the zebrafish brain, AGRP terminals overlap the denser MSH innervation but both AGRP and MSH neurons also independently project into several areas. The highest innervation is found within the rostral and magnocellular preoptic area and caudal tuberal hypothalamus where we have described profuse expression of the sea bass melanocortin $\mathrm{MC}_{4}$ receptor. The phenotype of the neurons expressing melanocortin $\mathrm{MC}_{4}$ receptor is unknown and deserves further investigation in the future but it is known that MSH terminals lie in close apposition to corticotrophin-releasing hormone-producing neurons in the posterior preoptic area of 
the goldfish (Matsuda et al., 2008). The preoptic and hypothalamic regions vary greatly among vertebrates. As described above, the lateral tuberal nucleus is thought to be the teleostean homologue of the mammalian arcuate nucleus, while the parvo- and magnocellular neurons of the preoptic nucleus seem to be homologues of the mammalian supraoptic and paraventricular nuclei, all of them pivotal points in the control of the energy balance in mammalian species (Berthoud, 2002). Neuronal pathways involved in the control of food intake in fish are not well known. However, the tuberal hypothalamus, lateral torus and the inferior hypothalamic lobe have been suggested as being involved in the integration of the viscero-sensory information and elaboration of coordinated responses modifying the energy balance in fish (Rink and Wulliman, 2002).

In summary, the results obtained in several fish species suggest that the melanocortin system may induce an inhibitory tone on food intake via constitutive activation of the central melanocortin $\mathrm{MC}_{4}$ receptor. This constitutive tone is mainly regulated by the binding of AGRP within the tuberal hypothalamus and preoptic area. Agonist binding would increase melanocortinic tone under particular physiological conditions. In support of this hypothesis, it has been reported that the overexpression of AGRP in zebrafish results in increased linear growth and total body weight. Transgenic AGRP fish also exhibit visceral adipocyte hypetrtrophia and increased total triglyceride levels suggesting that these fish are obese (Song and Cone, 2007). The absence of systemic $\alpha-\mathrm{MSH}$ also results in hyperphagia and obesity in rainbow trout. Therefore, the "cobalt” phenotype, sonamed because of its "cobalt-blue” body colour, has been attributed to the absence of most of the pars intermedia of the pituitary, where $\alpha-\mathrm{MSH}$ is synthesized. This variant of trout is hyperphagic and, typically, also has an enlarged liver and shows fat accumulation in the abdominal cavity, reflecting the absence of $\alpha$-MSH-mediated lipolytic activity (Yada et al., 2002). This suggests that the melanocortin system plays a dual role in the control of the energy balance by activating peripheral lipolytic activity, thus enhancing energy expenditure, and through the central inhibition of food intake. Experiments in sea bass have demonstrated that MSH can stimulate hepatic lypolisis via sea bass melanocortin $\mathrm{MC}_{5}$ receptor (Sánchez et al., 2009b) 


\section{Melanocortins and pigmentation}

Although more than 100 loci have been identified as being involved in vertebrate pigmentation, the melanocortin system is consistently a key determinant of the pigment phenotype. In mammals, the colour pattern is determined by the distribution of two pigments, pheomelanin (red/yellow) and eumelanin (brown/black). Both pigments are synthesized from a common precursor, dopaquinone, in response to respectively low or high levels of tyrosinase, the rate-limiting enzyme in the synthesis of melanins. Two main loci are responsible for the pheomelanin/eumelanin synthesis rate in the melanocyte- extension and agouti. The melanocortin $\mathrm{MC}_{1}$ receptor fills up the locus extension (Robbins et al. 1993) and regulates the synthesis of melanin via activation of tyrosinase. Briefly, $\alpha-\mathrm{MSH}$ activation of melanocortin $\mathrm{MC}_{1}$ receptor leads to increased intracellular levels of cAMP, which, in turn, lead to phosphorylation of the cAMP responsive-element-binding protein (CREB). CREB transcriptionally regulates several genes, including the transcription factor microphtalmia (MITF). MITF is pivotal in the expression of several pigment-synthesizing enzymes, including tyrosinase, and differentiation factors (Lin and Fisher, 2007). Therefore, melanocortin $\mathrm{MC}_{1}$ receptor activation, results in high levels of tyrosinase, which leads to eumelanogenesis and, by extension, to dark (brown/black) pigmentation (Sakai et al., 1997). Accordingly, recessive yellow mice (e/e) which exhibit an almost yellow fur have been demonstrated to carry a frameshift mutation between the fourth and fifth tramsmenbrane domain of melanocortin $\mathrm{MC}_{1}$ receptor, while a sombre phenotype $\left(E^{s o} / E^{s o}\right)$ that has almost entirely black fur exhibits a point mutation that confers constitutive activity to the melanocortin $\mathrm{MC}_{1}$ receptor (Robbins et al. 1993). Agouti-signalling protein fills up the agouti locus (Bultman et al., 1992). This paracrine factor is synthesized in the hair bulbs and is efficiently released to melanocytes and hair matrix cells to regulate melanin production (Matsunaga et al., 2000). Agouti-signalling protein binding to melanocortin $\mathrm{MC}_{1}$ receptor reduces the constitutive or $\alpha \mathrm{MSH}$-induced signalling, reducing MITF 
expression and resulting in lower tyrosinase levels than in the presence of high levels of cystein switches eumelanogenesis to pheomelanogenesis and by extension darker to paler (yellow/red) colour patterns (Sakai et al., 1997; Aberdam et al., 1998). A high degree of polymorphism in the ASP (Miltenberger et al., 2002) and epigenetic modifications (Cropley et al., 2006) result in a high variety of mutant phenotypes, ranging from all black ( $a / a)$ to a uniform yellow (Ay/a) hair coat. Non agouti (a/a) extreme phenotypes carrying inactivating mutations in ASP display black fur (Bultman et al., 1992). The unusual allele, Ay, consists of a large deletion in the non-coding regions that places ASP gene under the control of the Raly promoter, an ubiquitously expressed RNA binding protein. The associated phenotype is characterized by ubiquitous expression of AS gene, resulting in yellow fur, hyperphagia, hyperinsulinemia, increased linear growth, an increased propensity for developing tumors, premature infertility and maturity-onset obesity (Miller et al., 1993; Michaud et al., 1994). This metabolic syndrome is mediated by antagonizing $\alpha$-MSH signalling at the central melanocortin $\mathrm{MC}_{4}$ receptor that arbitrates the negative effects of melanocortin peptides on the energy balance (Lu et al., 1994). The ectopic expression of ASP in the brain mimics the action of AGRP, a central antagonist that regulates the inhibitory tone imposed by melanocortins on food intake at melanocortin $\mathrm{MC}_{3}$ and $\mathrm{MC}_{4}$ receptors (Cone, 2006). The regional and temporal expression of different ASP isoforms, produced by the usage of alternative promoters, is responsible for the dorsal ventral pigment pattern in mouse but also for the subapical yellow banding in the agouti coloration (Vrieling et al., 1994). Agouti-signalling protein not only modifies the switch from eumelanogenesis to pheomelanogenesis but also inhibits the differentiation of neural crest precursors into melanocytes (Aberdam et al., 1998; Sviderskaya et al., 2001). Microarray analyses of in vitro cultured melan-a melanocytes have suggested that cell treatment with ASP reproduces dedifferentiation stages by reducing the number of melanogenic proteins and increasing cell migration (Le Pape et al., 2009).

Typical fish colour patterns are obtained as a result of the combination of several types of chromatophores commonly found in the dermis. Pigment cells are divided into light-absorbing 
(melanophores, xantophores, erythrophores and cyanophores) and light-reflecting (leucophores and iridophores) chromatophores. Fish melanophores are known to contain only eumelanins (blackbrown pigments), whereas xantophores and erytrophores contain carotenoids and/or pteridines, which contribute to reddish and yellowish components of skin coloration. Iridophores are commonly localized in whitish and silvery areas of the skin, predominantly on the belly surface. They contain crystalline platelets composed of purines, mainly guanine, responsible for the reflection of the light. The interaction of light with the patterned distribution of pigmented cells creates the colour pattern in fish (Fuji, 1993). A common morphological pattern in many nonmammalian vertebrates is a sharp demarcation in the coloration between dorsal and ventral areas. In teleosts, this countershading is achieved by a patterned distribution of the pigment cells, with the light-absorbing and light reflecting chromatophores mostly distributed in the dorsal and ventral areas, respectively (Fuji, 1993). Early experiments in amphibian and fish species suggested that the dorsal-ventral pigment pattern is achieved through a putative diffusible melanization inhibition factor (MIF), mainly produced by cells in the ventral skin, which inhibits melanoblast differentiation and stimulates or supports iridophore proliferation in the ventrum (Fukuzawa and Ide, 1988, Bagnara and Fukuzawa, 1990, Zuasti et al., 1992; Zuasti, 2002). Amphibian MIF was reported to block stimulation of the melanization provoked by $\alpha$-MSH in neural explants of Xenopus (Fukuzaga and Bagnara, 1989). Subsequently, amphibian MIF was also shown to block $\alpha$ MSH-induced tyrosine hydroxylase and dopa oxydase activity in mouse malignant melanocytes, both key enzymes in the melanogenic pathway (López-Contreas et al., 1996). Although MIF has been partially purified and MIF-antibodies have localized its expression in the ventral skin of leopard frog (Rana forreri), the molecular structure remains unidentified (Fukuzaga et al., 1995). Similar experiments in catfish demonstrated that conditioned medium from catfish ventral skin and semi-purified amphibian MIF inhibits melanoblast differentiation but stimulates or supports iridophore proliferation (Zuasti, 2002).

Recent studies have demonstrated that the melanocortin system is also a key player in the 
establishment of the adult pigment pattern in fish. Frameshift mutations introducing a premature stop codon in melanocortin $\mathrm{MC}_{1}$ receptor or inactivating mutations in blind Mexican cave tetra (Astyanax mexicanus) are responsible for a decrease in the number of melanophores and in the melanin content. This phenotype was recapitulated by melanocortin $\mathrm{MC}_{1}$ receptor morpholino knockdown experiments in zebrafish (Gross et al., 2009). Our experiments in sea bass have demonstrated that sea bass melanocortin $\mathrm{MC}_{1}$ receptor is constitutively activated and expressed in both dorsal and ventral skin (Sánchez et al., 2010), suggesting that the ligand-independent activity of the receptor may be responsible for melanization in fish. If melanocortin $\mathrm{MC}_{1}$ receptor is constitutively activated and expressed in both dorsal and ventral surfaces, it would be difficult for fish to take on a dorsal ventral colour pattern. Therefore, the melanocortin $\mathrm{MC}_{1}$ receptor function is probably inhibited in the ventrum to help establish the pigment pattern. This model goes along with the presence of non-diffusible MIFs in the ventral area but not in the dorsal region (see above). Our recent studies in goldfish strongly suggest that ASP fish orthologue is non-mammalian MIF. Experiments in goldfish (Cerdá-Reverter et al., 2005) and pufferfish (Kurokawa et al., 2006) showed that ASPis mainly expressed in the ventral skin with very low levels in the dorsal skin. The identity of ASP-expression cells is still unknown. Recombinant goldfish ASP interacts with the melanocortin system, working as a competitive antagonist and probably as an inverse agonist to decrease both the NDP-MSH-induced and constitutive intracellular accumulation of cAMP in pufferfish melanocortin $\mathrm{MC}_{1}$ receptor and goldfish melanocortin $\mathrm{MC}_{4}$ receptor expressing cell lines. Goldfish ASP also inhibits NDP-MSH-induced melanosome movements (Cerdá-Reverter et al., 2005) and injection of capped goldfish ASP mRNA in the dorsal skin of flatfish, turbot (Scophthalmus maximus) and Senegalese sole (Solea senegalensis) dramatically inhibits melanization (Ceinos R, Guillot R, Rotllant P and Cerdá-Reverter JM, unpublished results). Therefore, our hypothesis is that melanocortin $\mathrm{MC}_{1}$ receptor constitutively drives melanization in fish skin but the inverse agonism of ASP in the ventral skin reduces melanocortin $\mathrm{MC}_{1}$ receptor activity, thus inhibiting both melanization and melanoblat differentiation but supporting iridophore 
proliferation. This hypothesis could be extended not only to melanization since red/orange goldfish lacking melanocytes also display a dorsal-ventral pigment polarity. ASP is mainly expressed within the ventral skin of xanthic goldfish, suggesting that ASP inhibits the differentiation of light absorbing chromatophores (Cerdá-Reverter et al., 2005). We also hypothesized that the site of MITF expression inhibition lies downstream of ASP effects. Zebrafish exhibits two subfunctionalized copies of MITF (Lister et al., 2001). MITFa is coexpressed with MITFb in the retinal pigment epithelium but not in the neural crest melanoblast, where only MITFa is expressed. A single base mutation in the MITFa results in the almost complete absence of melanophores throughout embryonic and larval development, an absence that persists during adulthood in the nacre phenotype but pigmented retinal epithelium.

In contrast to the absence of melanophores, nacre mutants show an approximate $40 \%$ increase in the number of iridophores (Lister et al., 1999). MITF has also been reported to be sufficient to direct the differentiation of medaka embryonic stem-like cells into melanocytes (Béjar et al., 2002) Nacre phenotype (inhibition of melanoblast differentiation and iridophore proliferation) resembles those inferred properties of poikilotherm MIF that we have hypothesized to be ASP.

Our experiments overexpressing ASP in transgenic zebrafish have demonstrated a dramatic reduction in the number of melanophores within the dark stripes and an increased number of iridophore, leading to a severe disruption of the stripe pattern that results into spotted "cheetahfish" (Guillot R, Ceinos R, Rotllant J and Cerdá-Reverter JM, unpublished results).

The involvement of components of the melanocortin system other than melanocortin $\mathrm{MC}_{1}$ receptor and ASP in the colour pattern regulation in fish should be also considered. We have demonstrated that melanocortin $\mathrm{MC}_{5}$ receptor is highly expressed within the ventral skin but not in the dorsal skin of the sea bass (Sánchez et al., 2009b). Similarly, goldfish melanocortin $\mathrm{MC}_{5}$ receptor is also expressed in the skin despite the lack of differentiation between dorsal and ventral areas (CerdáReverter et al., 2003b). Sea bass melanocortin $\mathrm{MC}_{4}$ receptor is not expressed in the skin (Sánchez et al 2009a) but a low level of sea bass melanocortin $\mathrm{MC}_{2}$ receptor expression was detected in both 
dorsal and ventral areas (Agulleiro M, Sánchez E and Cerdá-Reverter JM, unpublished results). In contrast, goldfish melanocortin $\mathrm{MC}_{4}$ receptor is expressed within the dorsal skin but not in the ventral area (Cerdá-Reverter et al., 2003b). AGRP could be also involved in the regulation of the colour pattern in fish since expression levels in the dorsal skin were higher than those observed in

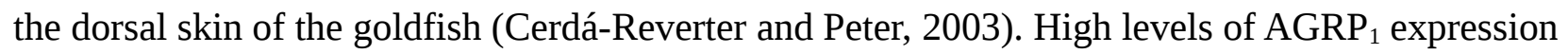
in the skin have been also reported in Atlantic salmon (Murashita et al., 2009) even though low levels were detected in pufferfish (Kurokawa et al., 2006) and sea bass (Agulleiro M, Sánchez E and Cerdá-Reverter JM unpublished results).

\section{Melanocortins and stress response}

As in other vertebrates, activation of the hypothalamus-pituitary-interrenal axis plays an essential role in the stress response in fish. Following stressor exposure, the hypothalamic neurons release corticotrophin-releasing hormone (CRF) to the anterior pituitary (rostral pars distalis) where the corticotropes are located. The processing of POMC in the corticotrophs leads to the production of ACTH, which activates melanocortin $\mathrm{MC}_{2}$ receptor in the interregnal tissue (analogous to the adrenal cortex in tetrapods), which, in turn, controls cortisol synthesis. Cortisol, the main corticosteroid in fish, is released to the blood to regulate a wide array of systems in both stressed and non-stressed animals (Wendelaar Bonga, 1997; Flik et al., 2006; Alsop and Vijayan 2009). Studies on HPI development have demonstrated that the stress response is organized early in the ontogenetic process. Maternal POMC mRNA is already present in fertilized eggs but endogenous expression begins 18 hours postfertilization and POMC pituitary cells are visible by whole-mount in situ hybridization as early as 24 hours postfertilization within the anterior domain (Hansen et al., 2003). These early corticotroph cells already respond to dexamethasone treatment (negative feeback) at $48 \mathrm{~h}$ hours postfertilization but interrenal development, as assessed by the expression of key esteroideogenic enzymes, is only sensitive after 5 days post fertilization. Interrenal tissue development seems to be independent of pituitary development on the first two days post 
fertilization. In fact, the expression of steroidogenic enzymes (22-28 hours postfertilization) precedes melanocortin $\mathrm{MC}_{2}$ receptor expression (32 hours postfertilization), and the expression pattern of the studied steroideogenic and chromafin genes is similar in mutants lacking pituitary cells (including corticotrophs). However, these mutants exhibit severe impairment of the interrenal function at 5 days postfertilization suggesting that proliferation and full functional differentiation of the interregnal organ depends on $\mathrm{ACTH} /$ melanocortin $\mathrm{MC}_{2}$ receptor interaction (To et al., 2007). A cortisol stress response is obtained at 4 days postfertilization in zebrafish but early exposure to stressors seems to influence normal hypothalamus-pituitary-interrenal axis development; in particular, the magnitude of cortisol response to stressors is reduced during adulthood (Alsop and Vijayan, 2009).

In adult rainbow trout, acute stressors rapidly elicit a significant increase in plasma ACTH (1 hour post-stress) and melanocortin $\mathrm{MC}_{2}$ receptor expression (4 hours post-stressor). This up-regulation of melanocortin $\mathrm{MC}_{2}$ receptor expression is clearly induced by the ACTH since in vitro incubation of interregnal slides with the hormone leads to an increase in the receptor expression. Using this in vitro system in rainbow trout, ACTH was able to induce an increase in cortisol synthesis that was not blocked by melanocortin $\mathrm{MC}_{4}$ receptor antagonist (SHU9119), but NDP-MSH was incapable of inducing cortisol release to the cell culture medium. This suggests that $\alpha-\mathrm{MSH}$ is not involved in the cortisol response to stress (Aluru and Vijayan, 2008) despite reports that melanocortin $\mathrm{MC}_{5}$ receptor is profusely expressed in the head kidney of the rainbow trout (Haitina et al., 2004). Similar results were also reported in carp even though $\alpha$-MSH levels were increased after 1 and 7 days of restraint stress. The superfusion of interrenal tissue with homogenate from the pars intermedia elicited an increase in cortisol release, suggesting the presence of unknown corticotrops in the above pituitary domain (Metz et al., 2005). In summary, it seems that, as in other vertebrates, melanocortin $\mathrm{MC}_{2}$ receptor is the main player in the cortisol response to stress.

The study of melanocortin $\mathrm{MC}_{2}$ receptor activation has been limited because of the lack of a readily transfectable heterologous expression system. Only adrenocortical-derived cell lines (Y6 or OS3), 
from which endogenous melanocortin MC receptor expression is absent, have rendered appropriate data on melanocortin $\mathrm{MC}_{2}$ receptor pharmacology (Schimmer et al., 1995). Expression experiments in a range of non-adrenal cells suggested that melanocortin $\mathrm{MC}_{2}$ receptor cannot reach the plasma membrane and is retarded in the endoplasmic reticulum, thus compromising its functional expression. This justification suggested the presence of an accessory factor that works as an melanocortin $\mathrm{MC}_{2}$ receptor-specific transport system in the adrenocortical cells (Noon et al., 2002). One gene candidate that encodes for a small single transmembrane domain protein with high expression in the adrenal cortex was identified in humans, showing familial glucocorticoid deficiency (FGD). This syndrome is characterized by resistance to ACTH, i.e. high plasma ACTH levels but lacking adrenal glucocorticoids. The protein is known as melanocortin $\mathrm{MC}_{2}$ receptor accessory protein (MRAP). The alternative splicing of the last two exons gives rise to two isoforms that differ in the C-terminal region (MRAP $\alpha$ and MRAP $\beta$ E є $;$; Metherell et al., 2005) E. Knockdown of endogenous mouse MRAP in Y1 adrenocortical cells, which express a functional endogenous melanocortin $\mathrm{MC}_{2}$ receptor, leads to insensitivity to $\mathrm{ACTH}$, demonstrating that MRAP is essential for producing an ACTH responsive melanocortin $\mathrm{MC}_{2}$ receptor (Cooray et al., 2008). MRAP interacts with the melanocortin $\mathrm{MC}_{2}$ receptor to facilitate correct folding, and subsequent glycosylation and receptor cell surface expression (Metherell et al., 2005) but they are also essential for ACTH binding and ACTH-induced cAMP production (Sebag and Hinkle, 2009a; Roy et al., 2007). Recent experiments have identified a second form of MRAP in the human genome called MRAP2. This protein shares the structural characteristics of MRAP but is expressed only in the human brain and adrenal gland. Similar to $\mathrm{MRAP}_{1}, \mathrm{MRAP}_{2}$ assists melanocortin $\mathrm{MC}_{2}$ receptor cell surface expression and allows the ACTH-induced cAMP production (Sebag and Hinkle, 2009a; Chan et al., 2009). Our preliminary experiments expressing sea bass melanocortin $\mathrm{MC}_{2}$ receptor in HEK-293 cells failed to generate an ACTH-stimulated cAMP increase. However, when human MRAPs were cotransfected, the sea bass melanocortin $\mathrm{MC}_{2}$ receptor was able to mediate ACTHinduced cAMP production, suggesting the presence of a conserved melanocortin $\mathrm{MC}_{2}$ receptor 
trafficking system in non-mammalian vertebrates.

In silico searches using available public databases rendered three different MRAPs in zebrafish, i.e.

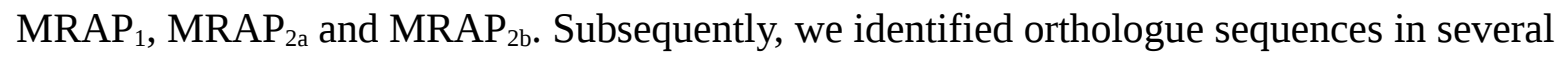
teleosts fish. MRAP1 is mainly expressed in the anterior kidney of the zebrafish presumably in the interregnal tissue but the cell type has not been identified. In contrast, both $\mathrm{MRAP}_{2 \mathrm{a}}$ and $\mathrm{MRAP}_{2 b}$ expression was found in every tissue tested. Cell trafficking studies demonstrated that zebrafish melanocortin $\mathrm{MC}_{2}$ receptor cannot reach plasma membrane when overexpressed in HEK-293 cells. When zebrafish or human MRAP 1 (Agulleiro MJ, Roy S, Gallo-Payet N and Cerdá-Reverter JM, unpublished results) was coexpressed together with zebrafish melanocortin $\mathrm{MC}_{2}$ receptor in the above cell system, both proteins were colocalized in the cell surface. However, when zebrafish melanocortin $\mathrm{MC}_{2}$ receptor was coexpressed with $\mathrm{MRAP}_{2 \mathrm{a}}$ or $\mathrm{MRAP}_{2 \mathrm{~b}}$, both receptor and accessory protein labelling fluorochromes were colocalized but never in the plasma membrane. Both zebrafish melanocortin $\mathrm{MC}_{2}$ receptor and $\mathrm{MRAP}_{2 \mathrm{a}}$ were mainly found in the cytoplasm, while zebrafish melanocortin $\mathrm{MC}_{2}$ receptor and $\mathrm{MRAP}_{2 \mathrm{~b}}$ were colocalized in the cytoplasm and also in the nuclear membrane (Agulleiro et al., 2010). Interestingly, it has been reported that mouse melanocortin $\mathrm{MC}_{2}$ receptor is complexed with nucleoporin 50 expressed in Y6 adrenal cells and translocated from the membrane to the nucleus after ACTH stimulation (Doufexis et al., 20007). Therefore, it is possible that MRAP2 may be involved in this novel signalling pathway. According to trafficking studies, zebrafish melanocortin $\mathrm{MC}_{2}$ receptor responds to $\mathrm{ACTH}$ stimulation only when co-expressed with zebrafish $\mathrm{MRAP}_{1}$ or human $\mathrm{MRAP}_{1}$, but not with zebrafish MRAP2a or MRAP2b, as seen from increases in the intracellular cAMP levels in HEK cells. The receptor did not became functional in the absence of $\mathrm{MRAP}_{1}$ but when $\mathrm{MRAP}_{2 \mathrm{a}}$ or $\mathrm{MRAP}_{2 \mathrm{~b}}$ were coexpressed together with $\mathrm{MRAP}_{1}$ in cells stably expressing zebrafish melanocortin $\mathrm{MC}_{2}$ receptor, the magnitude of the response was increased. This suggests that $\mathrm{MRAP}_{1}$ cooperates with the $\mathrm{MRAP}_{2}$ subtypes to increase the ACTH response (Agulleiro et al., 2010).

Developmental studies in zebrafish demonstrated that MRAP $_{1}$ expression is exclusively detected by 
whole-mount in situ hybridization in the interregnal tissue at 4 days post fertilization; however, studies revealing $\mathrm{MRAP}_{2 \mathrm{a}}$ and $\mathrm{MRAP}_{2 \mathrm{~b}}$ expression consistently detected diffuse expression within the brain at 2 days post fertilization. After 2 days, pituitary corticotrops are already responsive to dexamethasome but ACTH-dependent interregnal tissue development was noted at 5 days post fertilization (see above), suggesting that interregnal $\mathrm{MRAP}_{1}$ expression could be a crucial point in ACTH-dependent interrenal tissue development (Agullerio MJ, Guillot R, Sanchez and CerdáReverter, unpublished results). Incipient studies on $\mathrm{MRAP}_{1}$ promoter revealed putative recognition sites for peroxisome proliferator-activated receptor (PPAR), estrogen receptor (ER) and glucocorticoid receptors (GR), which suggests that $\mathrm{MRAP}_{1}$ is not only an accessory protein but a key point in the regulation of ACTH-induced glucocorticoid synthesis or, by extension, in the stress response in vertebrates.

\section{Acknowledgements}

This work was partially supported by grants from the Ministry of Science and Innovation (MICINN) AGL2007-65744-C03-02, CSD 2007-00002 and AGL2010-22247-C03-01 to JM C-R. MJA is recipient of a "Juan de la Cierva” research contract (2009) from the Spanish Science and Innovation Ministry. 


\section{References}

Aberdam, E., Bertolotto, C., Sviderskaya, E.V., de Thillot, V., Hemesath, T.J., Fisher, D.E., Bennett, D.C., Ortonne, J.-P., Ballotti, R., 1998. Involvement of microphthalmia in the inhibition of melanocyte lineage differentiation and melanogenesis by agouti signaling protein. J. Biol. Chem. 31, 19560-19565.

Agulleiro, M.J., Roy, S., Sánchez, E., Puchol, S., Gallo-Payet, N., Cerdá-Reverter, J.M., 2010. Role of accessory proteins in the function of zebrafish melanocortin receptor type 2. Mol. Cell. Endocrinol. 320, 145-152.

Alsop, D., Vijayan, M.M., 2009. Molecular programming of the corticosteroid stress axis during zebrafish development. Comp. Biochem. Physiol A. 153:49-54.

Aluru N, Vijayan MM., 2008. Molecular characterization, tissue-specific expression, and regulation of melanocortin 2 receptor in rainbow trout. Endocrinology 149, 4577-4588.

Bagnara, J.T., Fukuzawa, T., 1990. Stimulation of cultured iridophores by amphibian ventral conditioned media. Pigment Cell Res. 3, 243-250.

Bangol, D., Lu, X.-Y., Kaelin, C.B., Day, H.E.W., Ollmann, M., Gantz, I., Akil, H., Barsh, G.S., Watson, S.J.J., 1999. Anatomy of an endogenous antagonist: Relationship between agouti-related protein and proopiomelanocortin in brain. J. Neurosci. 19,1-7.

Bejar, J., Hong, Y., Schartl, M., 2002. Mitf expression is sufficient to direct differentiation of medaka blastula derived stem cells to melanocytes. Development 130, 6545-6553.

Berthoud, H.R., 2002. Multiple neural systems controlling food intake and body weight. Neurosci. Biobehav. Rev. 26, 393-428.

Bultman, S.J., Michaud, E.J., Woychik, R.P., 1992. Molecular characterization of the mouse agouti locus. Cell 71, 1195-1204.

Castro, M.G., Morrison, E., 1997. Post-translational processing of proopiomelanocortin in the pituitary and in the brain. Crit. Rev. Neurobiol. 11, 35-57.

Cerdá-Reverter, J.M., Canosa, L.F., 2009. Neuroendocrine Systems of the Fish Brain. In: Bernier, 
N.J., Van Der Kraak, G., Farrell, A.P., Brauner, C.J. (Eds.), Fish Neuroendocrinology. Fish Physiology 28, pp. 3-74.

Cerdá-Reverter, J.M., Peter, R.E., 2003. Endogenous melanocortin antagonist in fish. Structure, brain mapping and regulation by fasting of the goldfish agouti-related protein gene. Endocrinology 144, 4552-4561.

Cerdá-Reverter, J.M., Schiöth, H.B. Peter, R.E., 2003a. The central melanocortin system regulates food intake in goldfish. Regul. Pep. 115, 101-113.

Cerdá-Reverter, J.M., Haitina, T., Schiöth, H.B. Peter, R.E., 2005. Gene structure of the goldfish agouti-signaling protein: a putative role in the dorsal-ventral pigment pattern of fish. Endocrinology 146,1597-1610.

Cerdá-Reverter, J.M., Ling, M., Schiöth, H.B. Peter, R.E., 2003c. Molecular cloning, pharmacological characterization and brain mapping of the melanocortin 5 receptor in the goldfish. J. Neurochem. 87, 1354-1367.

Cerdá-Reverter, J.M., Ringholm, A., Schiöth, H.B., Peter, R.E. 2003b. Molecular cloning, pharmacological characterization and brain mapping of the melanocortin 4 receptor in the goldfish: Involvement in the control of food intake. Endocrinology 144, 2336-2349.

Chai, B.X., Neubig, R.R., Millhauser, G.L., Thompson, D.A., Jackson, P.J., Barsh, G.S., Dickinson, C.J., Li, J.Y., Lai, Y.M., Gantz, I., 2003. Inverse agonist activity of agouti and agouti-related protein. Peptides 24, 603-609.

Chan, L.F., Webb, T.R., Chung, T.T., Meimaridou, E., Cooray, S.N., Guasti, L., Chapple, J.P., Egertová, M., Elphick, M.R., Cheetham, M.E., Metherell, L.A., Clark, A.J., 2009. MRAP and MRAP2 are bidirectional regulators of the melanocortin receptor family. Proc. Natl. Acad. Sci. 106, 6146-6151.

Cone, R.D., 2006. Studies on the physiological functions of the melanocortin system. Endocr. Rev. 27, 736-749.

Cooray, S.N., Almiro Do Vale, I., Leung, K.Y., Webb, T.R., Chapple, J.P., Egertová, M., Cheetham, 
M.E., Elphick, M.R., Clark, A.J., 2008. The melanocortin 2 receptor accessory protein exists as a homodimer and is essential for the function of the melanocortin 2 receptor in the mouse y1 cell line. Endocrinology. 149, 1935-1941.

Cropley, J.E., Suter, C.M., Beckman, K.B., Martin, D.I., 2006. Germ-line epigenetic modification of the murine A vy allele by nutritional supplementation. Proc. Natl. Acad. Sci. USA 103,1730817312.

de Pedro, N., Delgado, M.J., Alonso-Bedate, M., 1995. Central administration of $\beta$-endorphin increases food intake in goldfish: pretreatment with the opioid antagonist naloxone. Regul. Pept. 55, 189-195.

de Souza, F.S., Bumaschny, V.F., Low, M.J., Rubinstein, M., 2005. Subfunctionalization of expression and peptide domains following the ancient duplication of the proopiomelanocortin gene in teleost fishes. Mol. Biol. Evol. 22, 2417-2427.

Doufexis, M., Storr, H.L., King, P.J., Clark, A.J., 2007. Interaction of the melanocortin 2 receptor with nucleoporin 50: evidence for a novel pathway between a G-protein-coupled receptor and the nucleus. FASEB J. 14, 4095-4100.

Forlano, P.M., Cone, R.D., 2007. Conserved neurochemical pathways involved in hypothalamic control of energy homeostasis. J. Comp. Neurol. 505, 235-248.

Fujii, R., 1993. Coloration and Chromatophores. In: Evans, D.H. (Ed.), The Physiology of Fishes. CRC press, Boca Raton, pp. 535-562.

Fukuzawa, T., Bagnara, J.T., 1989. Control of melanoblast differentiation in amphibia by $\alpha-M S H$, a serum melanization factor and a melanization inhibition factor. Pigment Cell Res. 2, 171-181.

Fukuzawa, T., Ide, H., 1988. A ventrally localized inhibitor of melanization in Xenopus laevis skin. Dev. Biol. 129, 25-36.

Fukuzawa, T., Samaraweera, P., Mangano, F.T., Law, J.H., Bagnara, J.T., 1995. Evidence that MIF plays a role in the development of pigment patterns in the frog. Dev. Biol. 167: 148-158.

Gerets, H.H.J., Peeters, K., Arckens, L., Vandesande, R., Berghman, L.R., 2000. Sequence and 
distribution of proopiomelanocortin in the pituitary and brain of the chicken (Gallus gallus). J. Comp. Neurol. 417, 250-262.

Gonzalez-Nunez, V., Gonzalez-Sarmiento, R., Rodríguez, R.E., 2003. Identification of two proopiomelanocortin genes in zebrafish (Danio rerio). Mol Brain Res. 120, 1-8.

Gross, J.B., Borowsky, R., Tabin, C.J., 2009. A novel role for Mc1r in the parallel evolution of depigmentation in independent populations of the cavefish Astyanax mexicanus. PLoS Genet. 5, e1000326.

Haitina, T., Klovins, J., Andersson, J., Fredriksson, R., Lagerström, M.C., Larhammar, D., Larson, E.T., Schiöth, H.B., 2004. Cloning, tissue distribution, pharmacology and three-dimensional modelling of melanocortin receptors 4 and 5 in rainbow trout suggest close evolutionary relationship of these subtypes. Biochem. J. 380, 475-486.

Hansen, I.A., To, T.T., Wortmann, S., Burmester, T., Winkler, C., Meyer, S.R., Neuner, C., Fassnacht, M., Allolio, B., 2003. The pro-opiomelanocortin gene of the zebrafish (Danio rerio). Biochem. Biophys. Res. Commun. 303, 1121-1128.

Henry, B.A., Rao, A., Ikenasio, B.A., Mountjoy, K.G., Tilbrook, A.J., Clarke, I.J., 2001. Differential expression of cocaine- and anphetamine-regulated transcript and agouti-related protein in chronically food-restricted sheep. Brain Res. 918, 40-50.

Henry, B.A., Tilbrook, A.J., Dunshea, F.R., Rao, A., Blache, D., Martin, G.B., Clarke, I.J., 2000. Long-term alterations in adiposity affect expression of melanin-concentrating hormone and enkephalin but not proopiomelanocortin in the hypothalamus of ovarectomized ewes. Endocrinology 141, 1506-1514.

Kobayashi, Y., Tsuchiya, K., Yamanome, T., Schiöth, H.B., Kawauchi, H., Takahashi, A., 2008. Food deprivation increases the expression of melanocortin-4 receptor in the liver of barfin flounder, Verasper moseri. Gen. Comp. Endocrinol. 155, 280-287.

Kurokawa, T., Murashita, K., Uji, S., 2006. Characterization and tissue distribution of multiple agouti-family genes in pufferfish, Takifugu rubripes. Peptides 27, 3165-3175. 
Le Pape, E., Passeron, T., Giubellino, A., Valencia, J.C., Wolber, R., Hearing, V.J., 2009. Microarray analysis sheds light on the dedifferentiating role of agouti signal protein in murine melanocytes via the Mc1r. Proc. Natl. Acad. Sci. USA. 106, 1802-1807.

Lin, J.Y., Fisher, D.E., 2007. Melanocyte biology and skin pigmentation. Nature 445: 843-850.

Lister, J.A., Robertson, C.P., Lepage, T., Johnson, S.L., Raible, D.W., 1999. nacre encodes a zebrafish microphthalmia-related protein that regulates neural-crest-derived pigment cell fate. Development. 126, 3757-3767.

Logan, D.W., Bryson-Richardson, R.J., Pagán, K.E., Taylor, M.S., Currie, P.D., Jackson, I.J. 2003. The structure and evolution of the melanocortin and MCH receptors in fish and mammals. Genomics 81, 184-191

López-Contreras, A.M., Martínez-Liarte, J.H., Solano, F., Samaraweera, P., Newton, J.M., Bagnara, J.T., 1996. The amphibian melanization inhibiting factor (MIF) blocks the ${ }^{ᄅ} \alpha$-MSH effect on mouse malignant melanocytes. Pigment Cell Res. 9, 311-316.

Lu, D., Willard, D., Patel, I.R., Kadwell, S., Overton, L., Kost, T., Luhter, M., Chen, W., Woychik, R.P., Wilkinson, W.O., 1994. Agouti protein is an antagonist of the melanocyte-stimulatinghormone receptor. Nature 371, 799-802.

Matsuda, K., Kojima, K., Shimakura, S., Wada, K., Maruyama, K., Uchiyama, M., Kikuyama, S., Shioda, S., 2008. Corticotropin-releasing hormone mediates alpha-melanocyte-stimulating hormone-induced anorexigenic action in goldfish. Peptides 11,1930-1936.

Matsunaga, N., Virador, V., Santis, C., Vieira, W.D., Furumura, M., Matsunaga, J., Kobayashi, N., Hearing, V.J., 2000. In situ localization of agouti signal protein in murine skin using immunohistochemistry with an ASP-specific antibody. Biochem. Biophys. Res. Commun. 270, 176-182.

Metherell, L.A., Chapple, J.P., Cooray, S., David, A., Becker, C., Rüschendorf, F., Naville, D., Begeot, M., Khoo, B., Nürnberg, P., Huebner, A., Cheetham, M.E., Clark, A.J., 2005. Mutations in MRAP, encoding a new interacting partner of the ACTH receptor, cause familial 
glucocorticoid deficiency type 2. Nat. Genet. 37, 166-170.

Metz, J.R., Peters, J.J., Flik, G., 2006. Molecular biology and physiology of the melanocortin system in fish: a review. Gen. Comp. Endocrinol. 148, 150-162.

Metz, J.R., Geven, E.J., van den Buró, E.H., Flik, G., 2005. ACTH, alpha-MSH, and control of cortisol release: cloning, sequencing, and functional expression of the melanocortin-2 and melanocortin-5 receptor in Cyprinus carpio. Am. J. Physiol. 289, R814-R826.

Michaud, E.J., Bultman, S.C., Stubss, L.J., Woychick, R.P., 1993. The embryonic lethally of homozygous lethal yellow mice (Ay/Ay) is associated with the disruption of a novel RNAbinding protein. Genes Dev. 7, 1203-1213.

Miller, M.W., Duhl, D.M.J., Vrieling, H., Cordes, S.P., Ollmann, M.M., Winkes, B.M., Barsh, G.S., 1993. Cloning of the mouse agouti gene predicts a secreted protein ubiquitously expressed in mice carrying a lethal yellow mutation. Genes Dev. 7, 454-467.

Miltenberger, R.J., Wakamatsu, K., Ito, S., Woychik, R.P., Russell, L.B., Michaud, E.J., 2002. Molecular and phenotypic analysis of 25 recessive, homozygous-viable alleles at the mouse agouti locus. Genetics. 160, 659-674.

Murashita, K., Kurokawa, T., Ebbesson, L.O., Stefansson, S.O., Rønnestad, I., 2009. Characterization, tissue distribution, and regulation of agouti-related protein (AgRP), cocaineand amphetamine-regulated transcript (CART) and neuropeptide Y (NPY) in Atlantic salmon (Salmo salar). Gen. Comp. Endocrinol. 162, 160-171.

Nakanishi, S., Inoue, A., Kita, T., Nakamura, M., Chang, A.C.Y., Cohen, S.N., Numa, S., 1979. Nucleotide sequence of cloned cDNA for bovine corticotropin- $\beta$-lipotropin precursor. Nature. 288, 610-613.

Nijenhuis, W.A., Oosterom, J., Adan, R.A., 2001. AgRP(83-132) acts as an inverse agonist on the human-melanocortin-4 receptor. Mol. Endocrinol. 15, 164-171

Noon, L.A., Franklin, J.M., King, P.J., Goulding, N.J., Hunyady, L., Clark, A.J., 2002. Failed export of the adrenocorticotrophin receptor from the endoplasmic reticulum in non-adrenal cells: 
evidence in support of a requirement for a specific adrenal accessory factor. J. Endocrinol. 174, 17-25.

Rink, E., Wulliman, M.F., 1998. Some forebrain connection of the gustatory system in the goldfish Carassius auratus visualized by separate DiI application to the hypothalamic inferior lobe and the torus lateralis. J. Comp. Neurol. 394, 152-170.

Robbins, L.S., Nadeau, J.H., Johnson, K.R., Kelly, M.A., Roselli-Rehfuss, L., Baack, E., Mountjoy, K.G., Cone, R.D., 1993. Pigmentation phenotypes of variant extension locus alleles result from point mutations that alter MSH receptor function. Cell 72, 827-834.

Roy, S., Rached, M., Gallo-Payet, N., 2007. Differential regulation of the human adrenocorticotropin receptor [melanocortin-2 receptor (MC2R)] by human MC2R accessory protein isoforms alpha and beta in isogenic human embryonic kidney 293 cells. Mol. Endocrinol. 21, 1656-1669.

Sakai, C., Ollmann, M., Kobayashi, T., Abdel-Malek, Z., Muller, J., Vieira, W.D., Imokawa, G., Barsh, G.S., Hearing, V.J., 1997. Modulation of murine melanocyte function in vitro by agouti signal protein. EMBO J. 16, 3544-3552.

Sánchez, E., Rubio, V.C., Cerdá-Reverter, JM., 2009b. Characterization of the sea bass melanocortin 5 receptor: a putative role in hepatic lipid metabolism. J. Exp. Biol. 212, 39013910.

Sánchez, E., Rubio, V.C., Cerdá-Reverter, J.M., 2010. Molecular and pharmacological characterization of the melanocortin receptor subtype 1 in the sea bass. Gen. Comp. Endocrinol. 65, 163-169.

Sánchez, E., Rubio, V.C., Thompson, D., Metz, J., Flik, G., Millhauser, G.L., Cerdá-Reverter, J.M., 2009a. Phosphodiesterase inhibitor-dependent inverse agonism of agouti-related protein (AGRP) on melanocortin 4 receptor in sea bass (Dicentrarchus labrax). Am. J. Physiol. 296, R1293R1306.

Schimmer, B.P., Kwan, W.K., Tsao, J., Qiu, R., 1995. Adrenocorticotropin-resistant mutants of the 
Y1 adrenal cell line fail to express the adrenocorticotropin receptor. J. Cell Physiol. 163, 164171.

Schiöth, H.B., Haitina, T., Ling, M.K., Ringholm, A., Fredriksson, R., Cerdá-Reverter, J.M., Klovins, J., 2005. Evolutionary conservation of the structural, pharmacological and genomic characteristics of the melanocortin receptors subtypes. Peptides 26, 1886-1900.

Schjolden, J., Schiöth, H.B., Larhammar, D., Winberg, S., Larson, E.T., 2009. Melanocortin peptides affect the motivation to feed in rainbow trout (Oncorhynchus mykiss). Gen. Comp. Endocrinol. 160, 134-138.

Sebag,. J.A., Hinkle, P.M., 2009. Regions of melanocortin 2 (MC2) receptor accessory protein necessary for dual topology and MC2 receptor trafficking and signalling. J. Biol. Chem. 284, 610-618.

Song, Y., Cone, R.D., 2007. Creation of a genetic model of obesity in a teleost. FASEB J. 9, 20422049.

Song, Y., Golling, G., Thacker, T.L., Cone, R.D., 2003. Agouti-related protein (AGRP) is conserved and regulated by metabolic state in the zebrafish, Danio rerio. Endocrine. 3, 257-65.

Stefano, G.B., Digenis, A., Spector, S., Leung, M.K., Bilfinger, T.V., Makman, M.H., Scharrer, B., Abumrad, N.N., 1993. Opiate-like substances in an invertebrate, an opiate receptor on invertebrate and human immunocytes, and a role in immunosuppression. Proc. Natl. Acad. Sci. USA. 90, 11099-11103.

Sundström, G., Dreborg, S., Larhammar, D., 2009. Concomitant duplications of opioid peptide and receptor genes before the origin of jawed vertebrates. PLoS One. 5, :e10512.

Sviderskaya, E.V., Hill, S.P., Balachandar, D., Barsh, G.S., Bennet, D.C., 2001. Agouti signaling protein and other factors modulating differentiation and proliferation of immortal melanoblast. Dev. Dyn. 221, 373-379.

Takahashi, A., Kawauchi, H., 2006. Evolution of melanocortin systems in fish. Gen. Comp. Endocrinol. 148, 85-94. 
Takahashi A, Kobayashi Y, Moriyama S, Hyodo S., 2008. Evaluation of posttranslational processing of proopiomelanocortin in the banded houndshark pituitary by combined cDNA cloning and mass spectrometry. Gen. Comp. Endocrinol. 157:41-48.

Takahashi, A., Amano, M., Itoh, T., Yasuda, A., Yamanome, T., Amemiya, Y., Sasaki, K., Sakai, M., Yamamori, K., Kawauchi, H., 2005. Nucleotide sequence and expression of three subtypes of proopiomelanocortin mRNA in barfin flounder. Gen. Comp. Endocrinol. 141, 291-303.

To, T.T., Hahner, S., Nica, G., Rohr, K.B., Hammerschmidt, M., Winkler, C., Allolio, B., 2007. Pituitary-interrenal interaction in zebrafish interrenal organ development. Mol. Endocrinol. 21, 472-485.

Tuinhof, R., Ubink, R., Tanaka, S., Atzori, C., van Strien, F.J.C., Roubos, E.W., 1998. Distribution of proopiomelanocortin and its peptide end products in the brain and hypophysis of the aquatic toad, Xenopus laevis. Cell Tissue Res. 292, 251-265.

Vrang, N., Larsen, P.J., Clausen, J.T., Kristensen, P., 1999. Neurochemical characterization of hypothalamic cocaine- amphetamine-regulated transcript neurons. J. Neurosci. 19, 1-8.

Vrieling, H., Duhl, D.M.J., Millar, S.E., Miller, K.A., Barsh, G.S., 1994. Differences in dorsal and ventral pigmentation result from regional expression of the mouse agouti gene. Proc. Natl. Acad. Sci. USA 91, 5667-5671.

Wendelaar Bonga, S.E., 1997. The stress response in fish. Physiol. Rev. 77, 591-625.

Yada, T., Moriyama, S., Suzuki, Y., Azuma, T., Takahashi, A., Hirose, S., Naito, N., 2002. Relationship between obesity and metabolic hormones in the "cobalt” variant of rainbow trout. Gen. Comp. Endocrinol. 128, 36-43

Young, J.I., Otero, V., Cerdán, M.G., Falzone, T.L., Chan, E.C., Low, M.J., Rubinstein, M., 1998. Authentic cell-specific and developmentally regulated expression of pro-opiomelanocortin genomic fragments in hypothalamic and hindbrain neurons of transgenic mice. J. Neurosci. 18, 6631-6640.

Zuasti, A., 2002. Melanization stimulating factor (MSF) and melanization inhibiting factor (MIF) in 
the integument of fish. Micros. Res. Tech. 58, 488-495.

Zuasti, A., Johnson, W.C., Samaraweera, P., Bagnara, J.T., 1992. Intrinsec pigment-cell stimulating activity in the catfish integument. Pigment Cell Res. 5, 253-262. 